\title{
Electrochemical efficacies of coal derived nanocarbons
}

\author{
Riya $\operatorname{Thomas}^{1} \cdot$ B. Manoj ${ }^{1}$ (D)
}

Received: 6 February 2020/Revised: 29 March 2020/Accepted: 22 October 2020/Published online: 6 December 2020

(C) The Author(s) 2020

\begin{abstract}
Carbon based nanomaterials are acknowledged for their admirable optical, electrical, mechanical characteristics and broad class of applications. Choice of precursor and simple synthesis techniques have decisive roles in viable production and commercialization of carbon produce. The intense demand to develop high purity carbon nanomaterials through inexpensive techniques has promoted usage of fossil derivatives as feasible source of carbon. Coal serves as a naturally available, abundant and cheap feedstock for carbon materials. From the crystalline clusters of aromatic hydrocarbons in a cross-linked network, carbon nanostructures can easily be extracted through green synthesis routes. It promotes a potent alternative for the cost effective and scaled up production of nanocarbon. The well-developed pores distribution, presence of numerous active sites and appropriate migration channels for ions enhance the electrochemical parameters necessary for the fabrication of supercapacitors, batteries and electrochemical sensors. The metallic impurities contained in coal contribute towards faradic redox reactions required for an efficient electrode modification. In this review, the potential uses of coal based carbon nanomaterials in energy storage and environmental sectors are discussed in detail.
\end{abstract}

Keywords Nano carbon $\cdot$ Coal $\cdot$ Supercapacitors $\cdot$ Energy storage

\section{Introduction}

Carbon based nanoparticles opened up a new frontier in material science through countless forms of derivatives and its unique set of remarkable properties (Foygel et al. 2005; Worsley et al. 2012). The form of allotropes varies from zero-dimensional Graphene Quantum Dots (GQDs) to special structures like onion-like and diamond-like carbons (Peng et al. 2012; Manoj and Kunjomana 2014; Das et al. 2016a, b; Manoj et al. 2017). These nanomaterials are poised to transmute futuristic applications of photovoltaics, energy storage, bioimaging, drug delivery and sensors exploiting its noteworthy physico-chemical characteristics (Liu et al. 2012; Shen et al. 2012; Manoj et al. 2018).

\section{B. Manoj}

manoj.b@christuniversity.in

1 Department of Physics \& Electronics, CHRIST, Bangalore, India
Despite the promising applications of nanocarbons, environmentally benign mass production at lower cost is a major issue that needs to be addressed. The conventional fabrication techniques for graphene, Carbon Nano Tube (CNT) and other carbon-based nanomaterials involve expensive carbon feedstock and time-consuming techniques (Awasthi et al. 2005; Riya and Manoj 2020). Thus, commercialization and practical applications of carbon materials are hindered due to the high cost of production. Consequently, a special attention is requisite for the choice of carbonaceous precursor and synthesis approaches regarding the viable production of carbon-based nanomaterials.

In this scenario, earth's abundant coal reserves can serve as a cost-effective and easily available feedstock for high purity nanocarbon derivatives. Coal is a naturally formed reserve of carbon majorly used as resource of energy through combustion for decades. Burning of coal results in the release of toxic gases such as carbon dioxide, nitrogen 
and sulphur dioxide which are hazardous for the environment. Hence a multipurpose utilization of coal at this stage will be very meaningful and well appreciated. Coal being a heterogeneous material which consist of 3D cross-linked framework of aromatic and hydro-aromatic units. Coal structure has got $\mathrm{sp}^{2}$ carbon domains arranged in a nanometer sized crystalline regime depending on the coalification degree (Mathews and Chaffee 2012). The amount of carbon concentration varies from $94 \mathrm{wt} \%$ to $70 \mathrm{wt} \%$ (Anthracite to Lignite) in the decreasing rank order of coal (Haenel 1992; O'Keefe et al. 2013). The possibility of an easier oxidative displacement of crystalline domains from coal compare to other pure forms (graphite) of $\mathrm{sp}^{2}$ domains further benefits the conversion of coal into various classes of carbon nanomaterials like Graphene, Graphene oxide, CNT, Carbon Nano Fibres (CNF), Nano spheres, GQDs, Porous carbon and Nano diamond (Fig. 1).

Based on the fact that low ranked coal generate more oxygen groups on the surface, Pakhira et al. (2015), extracted graphene oxide (GO) from a low grade coal simply through leaching with $\mathrm{HNO}_{3}$. On introduction of these flat sheets of GO into acidic medium, a clenched fists configuration was attained through the phenomenon named as "close-open sesame behaviour". Wherein, by using highly graphitized carbon network of anthracite, GO colloidal suspension was prepared via Hummer's method (Savitskii 2017). Vijapur et al. (2017) and Das et al. (2016a, b) demonstrated the exfoliation of graphene sheets from sub-bituminous coal. In fact, bulk amount of graphene could be derived from coal derived GO using different reducing techniques such as thermal treatment $(\mathrm{Wu}$ et al. 2013), hydrazine (Gao et al. 2014) and so on. Kumar et al. (2013) utilized bituminous coal for the fabrication of Single Walled Carbon Nanotubes (SWCNT) of diameter 1-2 nm (bundle length) via arc discharge method in support of $\mathrm{Zr} / \mathrm{Ni}$ catalyst. Similarly, Awasthi et al. (2015) obtained multiwalled CNT from bituminous coal without using any catalyst. In addition, Carbon Dots (CDs) and Graphene quantum dots exhibiting photoluminescence were prepared from coal via top-down approaches (Ye et al. 2013; Kundu et al. 2020). Affordable carbon-based nanomaterials could be derived from raw coal as the source for carbon (Table 1).

Size and functional group defects introduced in the carbon milieu through the synthesis process tune the bandgap and structural properties of the nanomaterials. The Bandgap of the GQDs could be controlled through oxidation of the nano structure in coal (Ye et al. 2013; Kundu et al. 2020). The morphological characteristics such as porous structures and surface chemistry are closely related to the electrochemical performance. Alteration in the structural configuration significantly augment electrical conductivity and chemical properties which in turn can be employed in electronic devices. The preformed crystalline facets in the coal resembles that of synthetic graphene. Apart from the carbon content, presence of other minerals such as $\mathrm{N}, \mathrm{Si}, \mathrm{Al}$ create heteroatom modified carbon matrix. Hence coal can be an efficient and cheap alternative material for graphene by avoiding the necessities of complex synthesis mechanisms and expensive production technologies. This review emphasizes on utilization of coal for the production of carbon novel structures, factors influencing the electrochemical performance and potential applications.

\section{Influential parameters}

\subsection{Rank of coal}

Coal rank is the measure of degree of coalification occurred. In other words, coal with the highest rank contains more amount of fixed carbon. Anthracite is the best quality coal, consisting 92\%-98\% of carbon with fewer impurities, followed by bituminous, sub-bituminous coal and lignite. More carbon content in the coal is an implication of larger carbon clusters available for the extraction of nanocarbon derivatives (Saikia et al. 2009; Meng et al. 2019). The polyaromatic structures in the coal resemble that of $\mathrm{sp}^{2}$ hybridisation characteristics of graphene. In highest rank coal, the aromatic structures have more crystallinity and dominating micropores gradually results in the formation of larger amount of aromatic carbon (Meng et al. 2019). The fall of $\mathrm{H} / \mathrm{C}$ ratio with aromaticity confirms the extent of graphitization (Fig. 2) (Manoj 2016; Xiao et al. 2019).

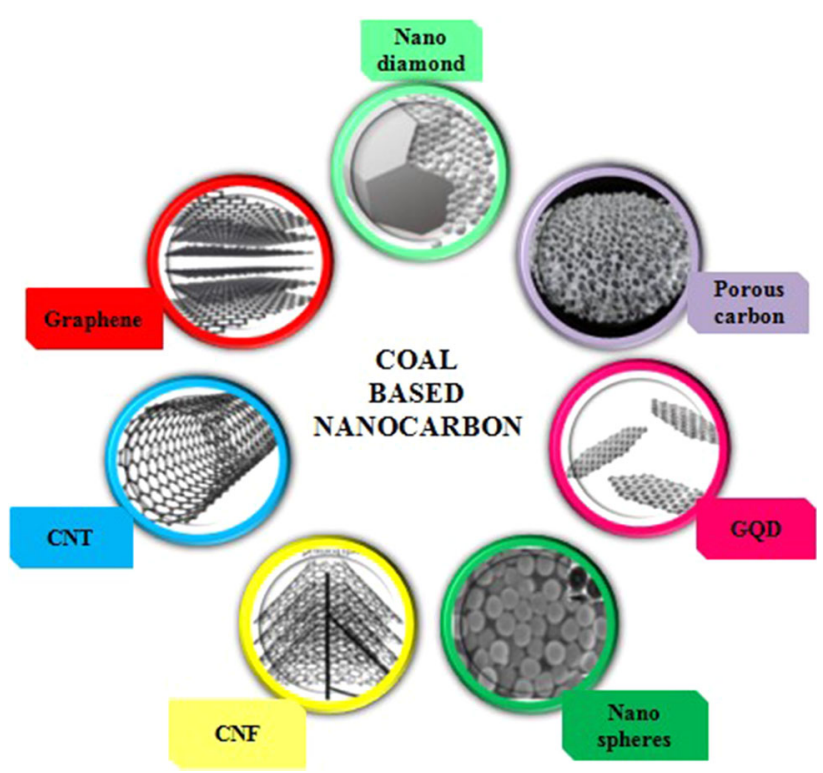

Fig. 1 Various forms of coal derived nanocarbon 
Table 1 Coal derived carbon based nanomaterials

\begin{tabular}{lllll}
\hline Nanostructure & Precursor & Technique & Character & References \\
\hline $\begin{array}{c}\text { Graphene } \\
\text { oxide }\end{array}$ & Anthracite & Hummers & $L_{\mathrm{a}}=122 \mathrm{~nm}$ & $\begin{array}{c}\text { Sierra et al. (2016), Fernández-García et al. (2017), } \\
\text { Savitskii (2017) }\end{array}$ \\
& $\begin{array}{l}\text { Industrial coal } \\
\text { liquid }\end{array}$ & Hummers & $L_{\mathrm{c}}=1.2 \mathrm{~nm}$ & \\
& Coal tar & Hummers & $L_{\mathrm{a}}=300 \mathrm{~nm}$ & \\
Graphene & Sub-bituminous & CVD & $I_{\mathrm{D}} / I_{\mathrm{G}} \sim 1$ & Xu et al. (2014), Das et al. (2016a, b), Vijapur et al. \\
& Sub-bituminous & Oxidation-cum- & $I_{\mathrm{D}} / I_{\mathrm{G}}=1.81$ & (2017) \\
& Coal tar pitch & extraction & $I_{\mathrm{D}} / I_{\mathrm{G}}=0.26$ & \\
& & Pyrolysis & & \\
CNT & Bituminous & Arc-discharge & Diameter $=50 \mathrm{~nm}$ & Li et al. (2012), Kumar et al. (2013), Awasthi et al. \\
& Bituminous & Arc-discharge & Diameter $=8 \mathrm{~nm}$ & (2015) \\
Carbon & Anthracite & Arc-discharge & Diameter $=40 \mathrm{~nm}$ & \\
nanofiber & Bituminous & Electrospinning & $S_{\mathrm{BET}}=142.670 \mathrm{~m} / \mathrm{g}$ & Tong et al. (2019), Zhao et al. (2020) \\
GQDs & Raw coal & Electrospinning & $S_{\mathrm{BET}}=821 \mathrm{~m} / \mathrm{g}$ & \\
& Bituminous & Acidic oxidation & Bandgap $=2.4-2.5 \mathrm{eV}$ & Ye et al. (2013), Kundu et al. (2020) \\
& Anthracite & Acidic oxidation & Bandgap $=3.4-3.6 \mathrm{eV}$ & \\
\hline
\end{tabular}

Thus, it helps in the fabrication of high-quality graphenebased nanostructures with high surface area and more open porous structures for better electrochemical performance.

Lignite being the lowest rank coal has high heteroatom content and low aromaticity. Coal rank effectively manipulates porous structure and electrochemical activity. It is the volatilization of small molecules during carbonization which induces pores. Hence with progressive rise of the coal rank, surface area of coal derived nanocarbon gradually reduces. Whereas, the increase in crystallinity contributes to lower charge transfer resistance at electrode-electrolyte interface (Zhang et al. 2012).

\subsection{Structural characteristics}

An accessible high active area and hierarchical pore structures are exceptional aspects for the surged utilization of coal in electrochemical devices. In reference to the zerodimensional structures, the conjugated carbon skeleton of Graphene Quantum Dots (GQDs) can construct complex and conductive assembly flexible for migration property (Li et al. 2016). The active sites at the enriched edges establish hybrid capacitive energy storage mechanisms (Wu et al. 2012). The 1D nanostructure like carbon nanofibers (CNF) provides not only high surface area, but also rapid transportation and penetration of ions along the fiber diameter. The empty spaces in the CNF could accommodate the volume changes due to the kinetic reactions through its stable structures and thereby furnish excellent cycle durability for electrode material (Tong et al. 2019). Wherein; 2D and 3D porous carbon network bestow lamellar porous structure with plentiful energy storage sites and multidimensional electron transport pathways (Stankovich et al. 2006). The storage and diffusion of ions were made possible through micropores and mesopores respectively while macropores serve the purpose of acting as a reservoir for electrolyte (Lu et al. 2017).

\subsection{Surface compositions}

Raman analysis of coal of different rank (Bituminous coal-B1H, sub-bituminous coal- $\mathrm{G} 1 \mathrm{H}$ and Lignite$\mathrm{L} 1 \mathrm{H})$ are presented in Fig. 3. The study revealed the existence of G-band attributed to the first order scattering of $E_{2} g$ mode of graphene. The $\mathrm{sp}^{3}$ domains at $1355 \mathrm{~cm}^{-1}$ is due to the defect band (D-band) leading to the edge planes and disordered structures. In case of sub-bituminous and bituminous coal, 2D band originates from the double resonance process is broad. It indicates formation of 4-5 graphene layers. This characteristic peak was not noticed for lignite $(\mathrm{L} 1 \mathrm{H})$, suggesting its bulk graphitic nature.

An optimal electrical and electrochemical behaviour of carbon materials are truly dependent on the defect density. The common causes for defects are distortion of carbon atoms, out of plane atoms and presence of impurities. The defect is boundary like in the case of bituminous and subbituminous coal whereas vacancy like defect is observed in low rank coal like lignite (Elcey and Manoj 2016) (Table 2).

Abundance of oxygen functionalities in the carbon layers establish advanced permeation of electrode material with electrolyte for a progressive electrochemical activity (Miao et al. 2019). Presence of Oxygen Functional Groups (OFG) attached to the surface of carbon can facilitate storage of ions. The expansion in the inter-layer spacing of 

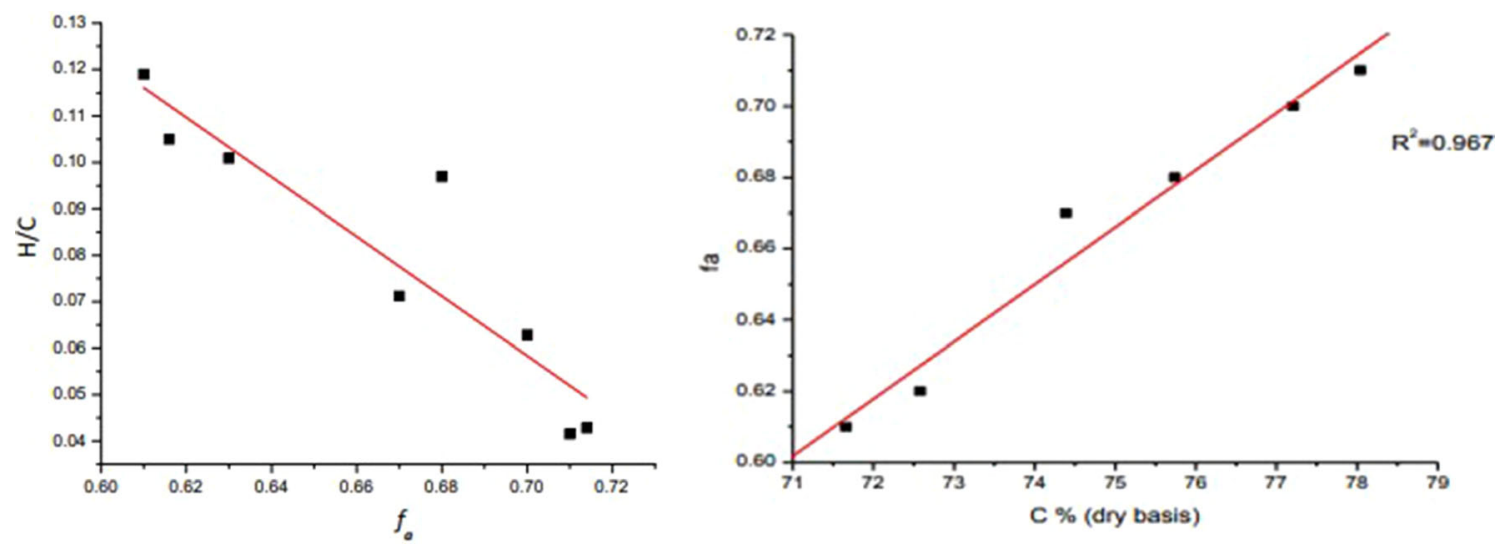

Fig. 2 a Variation of aromaticity $\left(f_{a}\right)$ vs. H/C ratio. b Variation of carbon content vs. aromaticity ( $\left.f_{a}\right)$ (Manoj 2016; Manoj and Kunjomana 2012). (Reprinted with permission from the publisher)

carbon layers due to the intercalation of oxygen groups can construct migration canals for ions. This carboxyl group can also attribute to increased adhesion of carbonaceous material to the electrode eliminating the need of binder. Input of OFG to the psuedocapacitance and electrochemical kinetics are very vital for the capacitance contribution.

Nevertheless, either the increase in surface area or psuedocapacitance will not provide superior charge exchange dynamics required for an efficient electrode modification; an increase in micropores hinders transportation of ions, and an increase in psuedocapacitance lead to low reaction rates (Jurewicz et al. 2008). This issue can be resolved through the enrichment of nitrogen like elements in the carbon matrix. This heteroatom creates electron donating effects at the edges of carbon-net which favour faradic redox reactions. It also helps in improvement of the wettability of electrode and provides electrostatic interactions needed for the psuedocapacitance.

\section{Potential utilizations}

\subsection{Supercapacitor electrode materials}

The electrochemical performance of coal derived nanocarbons emphasizes their physical and chemical properties with high surface area. Nanocarbon was synthesized from anthracite coal upon intercalation with $\mathrm{Li}$-ion exhibit high energy density and mesoporic surface (Benoy et al. 2020). Electrode material owns stable capacitive process and symmetric cyclic voltammograms without any redox peaks. At a scan rate of $10 \mathrm{mV} / \mathrm{s}$, specific capacitance of $65.4 \mathrm{~F} / \mathrm{g}$ and retention upto 200 cycles was achieved. Undistorted triangular waveform observed in the chronopotentiometry suggests the cyclic stability. Singh et al. (2020) synthesized water-soluble graphene sheets from bituminous coal via acidic oxidation. This micro- sized graphene sheets as an electrode material exhibited specific capacitance of $277 \mathrm{~F} / \mathrm{g}$ and a long cyclic stability ( $\sim 91 \%$ ) after 2000 cycles at a current density of $10 \mathrm{~mA} / \mathrm{g}$ (Fig. 4). 3D hollow porous graphene balls with a surface area of $1871 \mathrm{~m}^{2} / \mathrm{g}$ was prepared by He et al. (2014) from coal tar pitch (coke + coal gas). The enhanced electrical conductivity and abundant porosity in a balanced ratio contributed towards large specific capacitance of $321 \mathrm{~F} / \mathrm{g}$ at $50 \mathrm{~mA} / \mathrm{g}$. Capacitance retention of $94 \%$ was achieved after 1000 cycles in $6 \mathrm{M} \mathrm{KOH}$ at $100 \mathrm{~mA} / \mathrm{g}$. Similarly, a 3D interconnected graphene capsules were prepared from coal tar pitch providing free pathways for quick ion transport and adsorption (He et al. 2017). The material showed a capacitance of $277 \mathrm{~F} / \mathrm{g}$ at $50 \mathrm{~mA} / \mathrm{g}$ and $97 \%$ of capacitance could be retained over 15000 charge/discharge cycles due to its unique capsule nanostructure. The authors fabricated hierarchical porous carbon spheres from carboxylated coal tar pitch having high amount of easily wettable hydrophilic carboxyl groups (Wang et al. 2019). The sample with maximum surface area of $2669 \mathrm{~m}^{2} / \mathrm{g}$ demonstrated a capacitance of $286 \mathrm{~F} / \mathrm{g}$ at a current density of $2 \mathrm{~A} / \mathrm{g}$. The capacitance retention ratio close to $94 \%$ demonstrated the superior cycle stability of an electric double capacitor even after 10000 cycles. Riya and Balachandran (2020) extracted high-quality graphite structures from coke possessing a specific capacitance of $192 \mathrm{~F} / \mathrm{g}$ at current density of $0.2 \mathrm{~A} / \mathrm{g}$ and exhibited excellent capacitance retention over 2500 cycles. The lower internal resistance value obtained from the Nyquist plot suggests better charge propagation at the electrode interface which can assist in higher conductivity.

A report by Zhou et al. (2012) explains the preparation of graphene sheets from a graphitized anthracite coal exhibiting excellent electrochemical performance in $\mathrm{KOH}$ electrolyte. The high quality graphene sheets consist of several open structures which contribute to higher surface area as well as higher conductivity. These qualities 

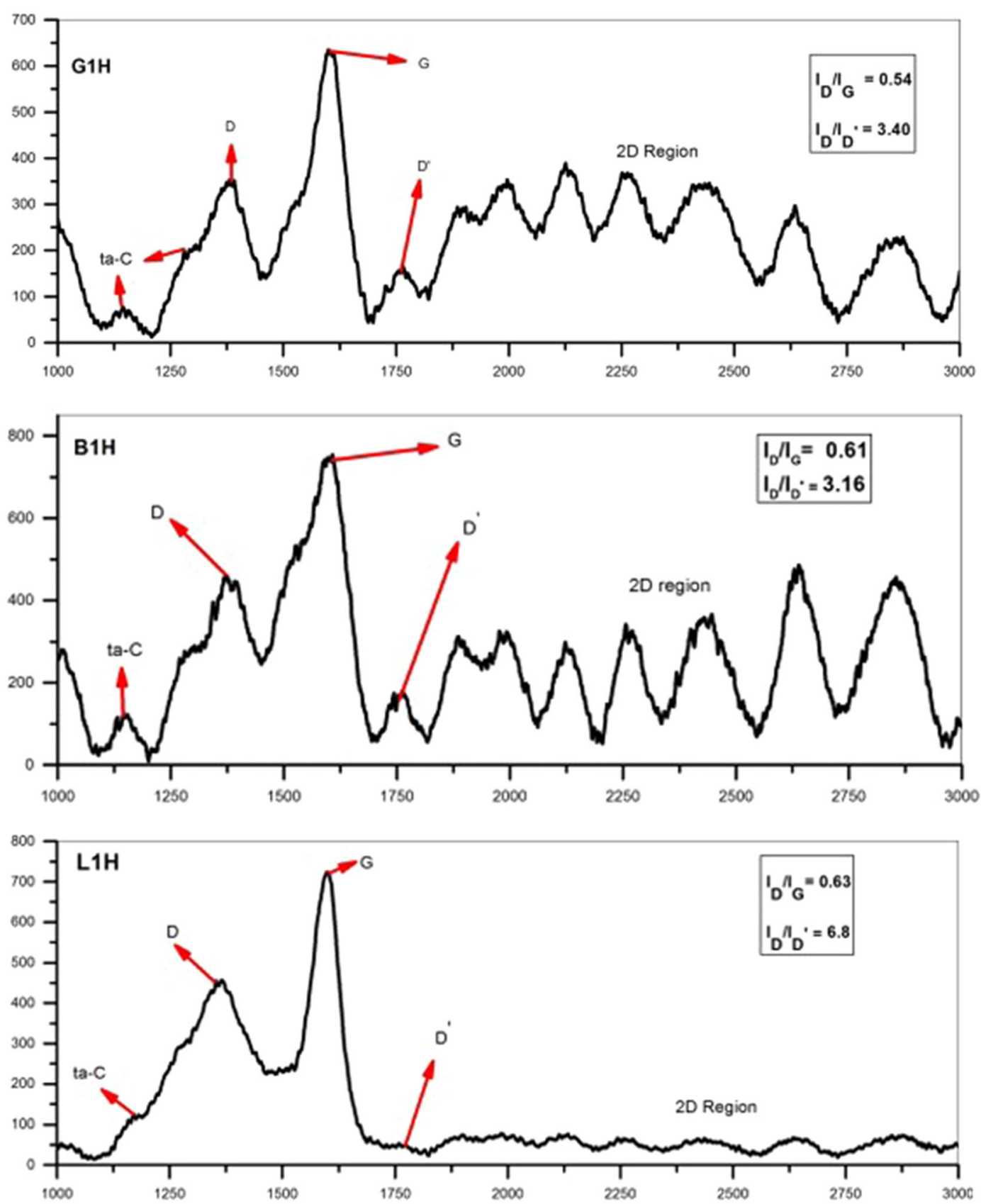

Fig. 3 Raman spectra of a Sub-bituminous coal—G1H b bituminous coal—B1H c Lignite—L1H (Elcey and Manoj 2016). (Reprinted with permission from the publisher)

significantly improved the electrochemical performance and attained a specific capacitance value of $200 \mathrm{~F} / \mathrm{g}$ at

Table 2 Structural parameters of various coals (Elcey and Manoj 2016)

\begin{tabular}{lllll}
\hline Item & Coal rank & $I_{\mathrm{D}} / I_{\mathrm{G}}$ & $I_{\mathrm{D}} / I_{\mathrm{D}}$ & Type of defect \\
\hline Sub-bituminous & 2.48 & 0.54 & 3.40 & Boundary-like \\
Bituminous & 1.51 & 0.58 & 3.16 & Boundary-like \\
Lignite & 0.77 & 0.63 & 6.80 & Vacancy-like \\
\hline
\end{tabular}

$50 \mathrm{~mA} / \mathrm{g}$. Seventy percent coulombic efficiency was obtained after 1000 galvanostatic charge/discharge cycles at $100 \mathrm{~mA} / \mathrm{g}$ (Fig. 5). Zhang et al. (2017) fabricated carbon nanosheets of hierarchical pore distribution by assembling bituminous coal-based graphene quantum dots. This interconnected graphene structure constructs a loose stacking with numerous active sites and appropriate ion migration channels. The high specific surface area of $1450 \mathrm{~m}^{2} / \mathrm{g}$ shows a specific capacitance of $230 \mathrm{~F} / \mathrm{g}$ indicating the better capacitive behaviour. The capacitance 
value remains invariant during 10,000 cycles under the experimental current of $10 \mathrm{~A} / \mathrm{g}$.

Sub-bituminous coal derived porous carbon nanosheets were employed as an active electrode material for supercapacitor (Das et al. 2017). Better rectangular shape of the cyclic voltammograms and the large area under the curve resembles the electric double layer behaviour of the nanosheets. Specific capacitance value of $125 \mathrm{~F} / \mathrm{g}$ was reported with a good cyclic stability up to 1000 measured cycles. The higher power delivering capability was confirmed through the lower value of the response time $\left(\tau_{0}\right)$ from EIS studies. Rate performance of activated carbon was significantly improved by embedding graphene quantum dots prepared from bituminous coal (Qing et al. 2019). It contributes towards a conductive network with affluence migration kinetics of ions and transfer of charges, wherein the formation of microporous structure with a specific surface area of $2829 \mathrm{~m}^{2} / \mathrm{g}$ facilitates the storage and transportation of ions. The composite showed excellent capacitive activity much higher than the activated carbon with a maximum value of $388 \mathrm{~F} / \mathrm{g}$ under the operation of $1 \mathrm{~A} / \mathrm{g}$. The ultrahigh energy of $13.47 \mathrm{~W} \mathrm{~h} / \mathrm{kg}$ obtained from the fabricated symmetric supercapacitor showcase its possibilities in energy storage devices.
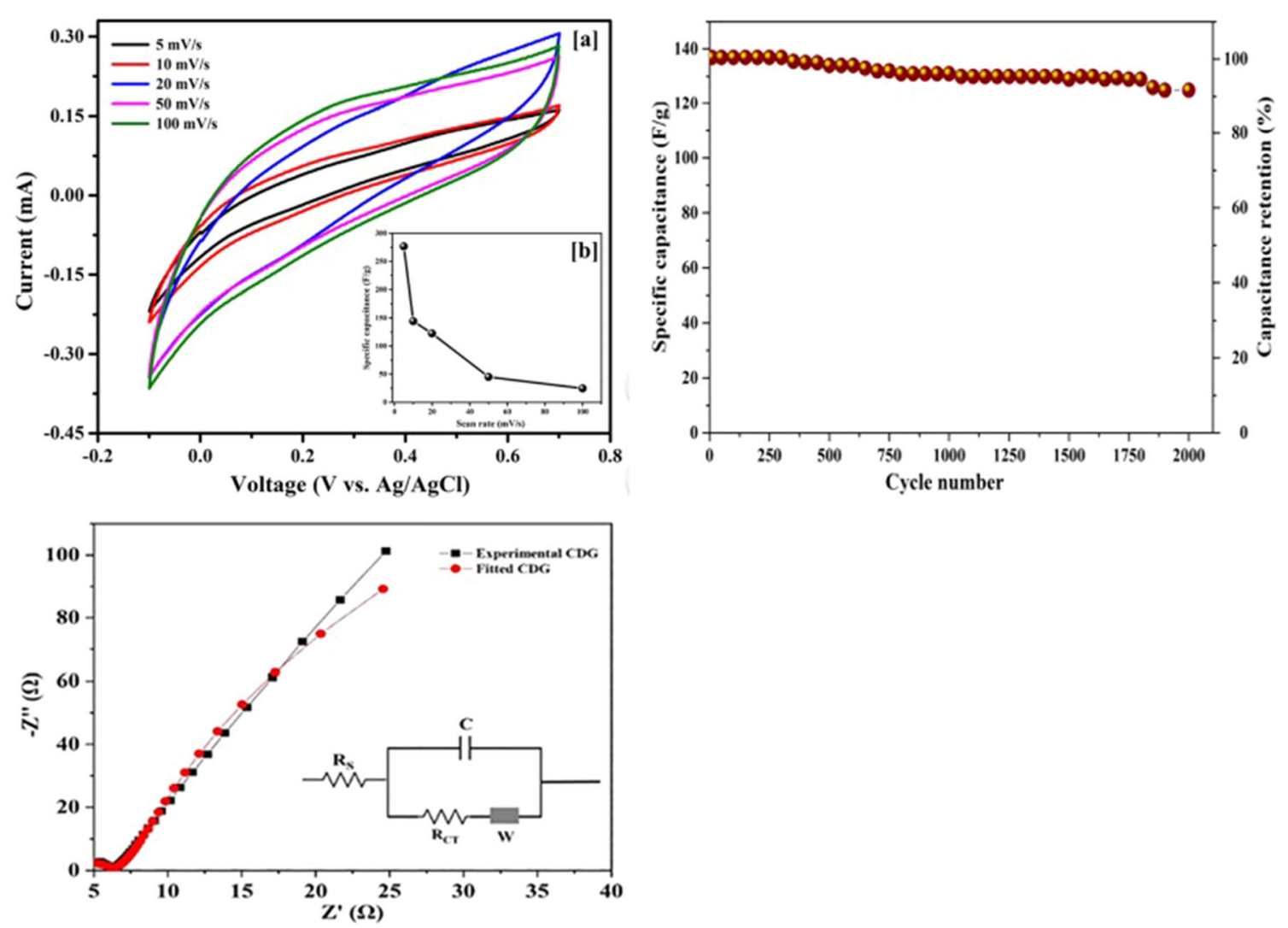

Graphene based composites prepared from coal was also employed for novel applications in supercapacitors. The high compatibility between carbon material and foreign nanoparticles in a composite facilitate both faradic and non-faradic charge storage mechanism in single electrode material. When carbon based derivatives that possess high surface area are mixed with metal/metal oxide, polymer or 2D inorganic nanostructures, contribution of pseudocapacitance also arises along with electric double layer capacitance. These hybrid nanocomposites have enhanced electrochemical properties, stability and mechanical flexibility than pristine carbon electrodes.

Gao et al. (2014) fabricated a graphene/ $\mathrm{Mn}_{3} \mathrm{O}_{4}$ composites using graphitized anthracite coal as carbon precursor. The synergetic effects in the hybrid constitute a conductive substrate for the efficient electron transfer from graphene and psuedocapacitance arise from $\mathrm{Mn}_{3} \mathrm{O}_{4}$ nanoparticles. This perfect combination improves the electrochemical utilization as supercapacitor electrodes of high stability and reversibility. At a current density of $50 \mathrm{~mA} / \mathrm{g}$, a specific capacitance of $260 \mathrm{~F} / \mathrm{g}$ was achieved in $\mathrm{K}_{2} \mathrm{SO}_{4}$ electrolyte solution (Fig. 6).

A synergistic electrochemical performance of cobalt dispersed bituminous coal based activated carbon was

Fig. 4 a Cyclic voltammetry curve for different scan rate. b Capacitance retention vs. cycle number. c Nyquist plot of the electrode modified using graphene sheets prepared from bituminous coal (Singh and Ojha 2020). (Reprinted with permission from the publisher) 

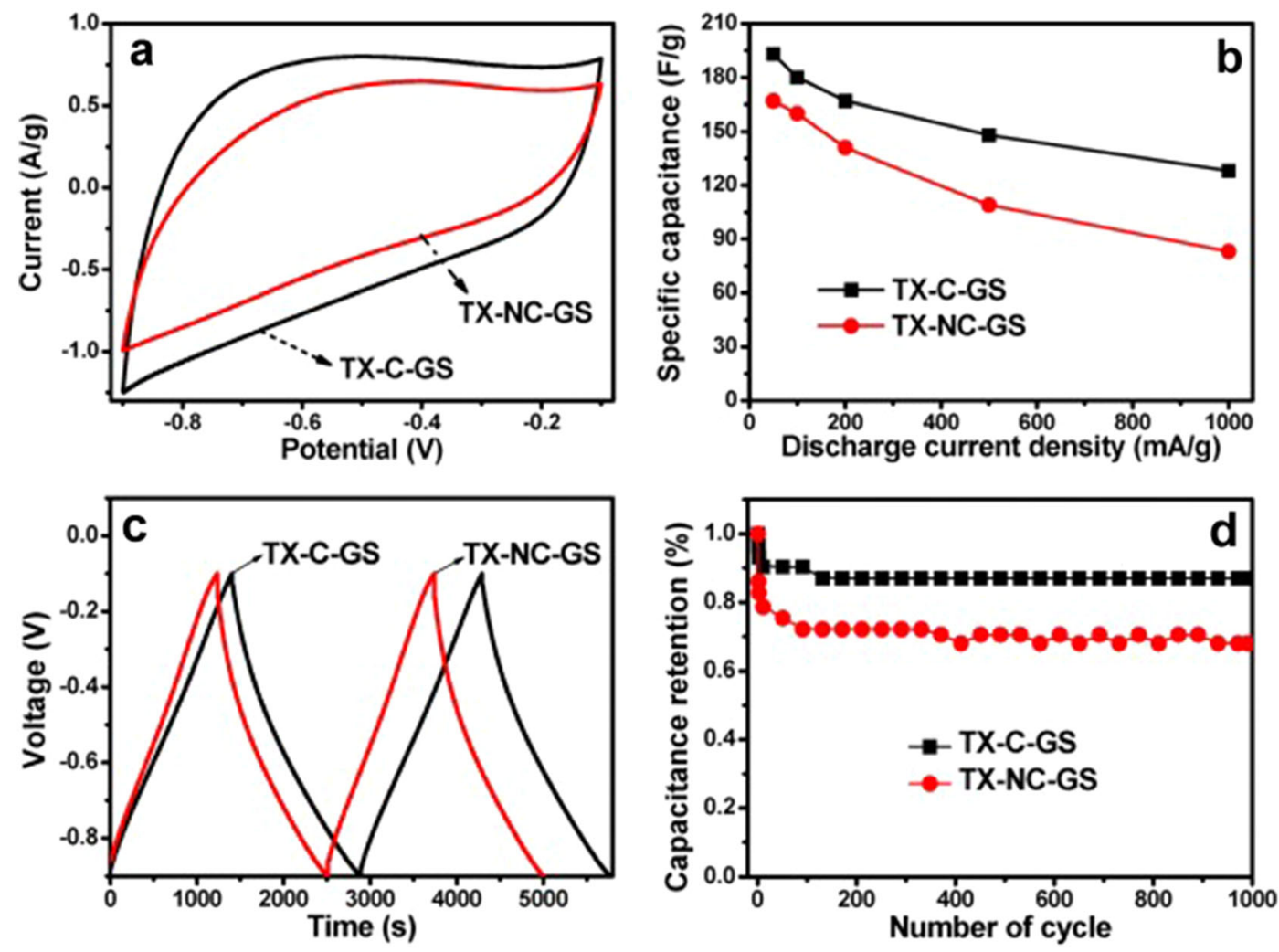

Fig. 5 a Cyclic voltammetry curves of graphene sheets obtained from bituminous coal at scan rate of $5 \mathrm{mV} / \mathrm{s}$. b Specific capacitance vs. Discharge current density. c GCD curves at $100 \mathrm{~mA} / \mathrm{g}$. d Cyclic performance at $100 \mathrm{~mA} / \mathrm{g}$ (Zhou et al. 2012). (Reprinted with permission from the publisher)

reported by Zhu at al. (2017). The activated carbon offers a platform for the uniform dispersion of Co nanoparticles restraining from agglomeration contributing towards enhanced electrochemical activity. The composite delivers high specific capacitance of the value $615 \mathrm{~F} / \mathrm{g}$ at current density of $2 \mathrm{~A} / \mathrm{g}$. Capacitive retention of $91.7 \%$ demonstrates the impressive rate capability of pseudocapacitive composite material. Jurewicz et al. (2008) utilized brown coal (Lignite) for developing high porous active carbon enriched with nitrogen. The electrochemical study of the sample reveals capacitance of $341 \mathrm{~F} / \mathrm{g}$ in negative electrode and $264 \mathrm{~F} / \mathrm{g}$ in positive electrode. Desirable capacitive performance of the material as negative electrode makes them a suitable match for high power capacitors in alkaline medium. Meanwhile, a report by Tong et al. explained a green synthesis route for the making of porous carbon nanofibers from lignite (Tong et al. 2019). The large surface area and mesoporous structure of sample benefits the structural stability and enhanced electrochemical performance. Particularly, a high specific capacitance of $265 \mathrm{~F} / \mathrm{g}$ was attained at $1 \mathrm{~A} / \mathrm{g}$ and a superior cyclic stability without much capacitance loss over 20,000 charge/ discharge cycles. This study provides a green way for the high-value consumption of coal in energy storage as supercapacitor electrodes. A major electrode modification for energy storage was accomplished using bituminous coal based nanocarbon. Even though highest rank coal can contribute towards more crystalline clusters, it is the volatilization of other small molecules (mineral, metallic impurities) which constitutes porosity in the carbon structures. A coal of middle rank can facilitate both crystallinity and pores induced high surface area in favour of energy storage device fabrication.

\subsection{Anode materials in batteries}

Gao et al. (2018) fabricated porous carbon from bituminous coal leading to hierarchical structures suitable for Lithium ion batteries (LIB). The well-developed pores act as ion buffering reservoirs as well as favourable channels for transmission of ions via electrolyte. As an anode material in LIB, a reversible capacity of $450 \mathrm{~mA} \mathrm{~h} / \mathrm{g}$ at $200 \mathrm{~mA} / \mathrm{g}$ was exhibited after 100 cycles and a high rate capability. After 450 cycles of consecutive galvanostatic charge-discharge, coulombic efficiency of $\sim 99 \%$ could be achieved (Fig. 7). Carbon nanotube is a promising electrode for LIBs and was extracted from bituminous coal by $\mathrm{Li}$ et al. (2017a). The nanotube got a special bamboo-like structure 

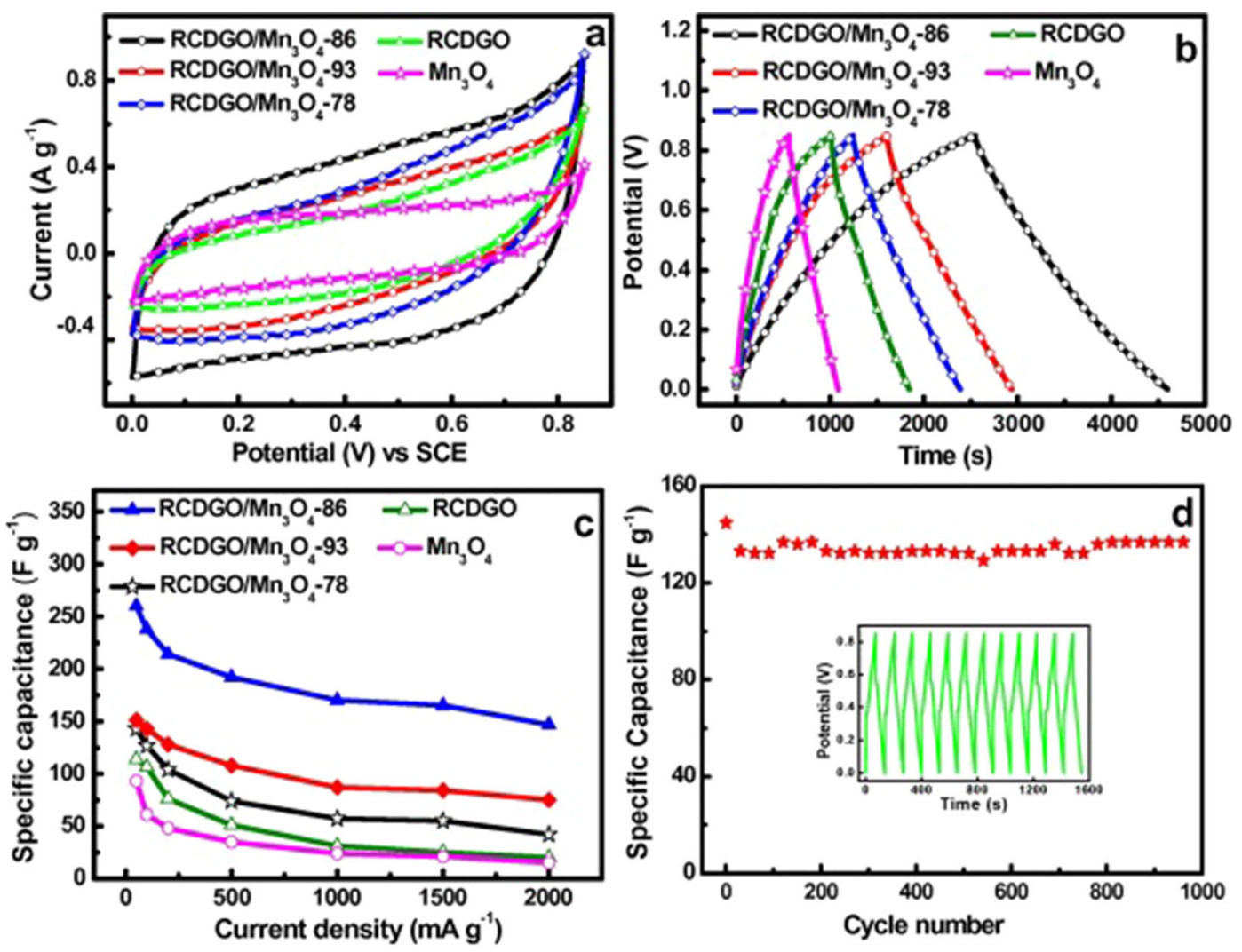

Fig. 6 a Cyclic voltammetry curves at scan rate of $5 \mathrm{mV} / \mathrm{s}$ of anthracite based graphene $/ \mathrm{Mn}_{3} \mathrm{O}_{4}$ composites. b GCD curves at $100 \mathrm{~mA} / \mathrm{g}$. c Specific capacitance vs. current density. d Cyclic performance at $2 \mathrm{~A} / \mathrm{g}$ (Gao et al. 2014). (Reprinted with permission from the publisher)

promoting reversible lithium storage via enlarged electrode-electrolyte interface and reduced diffusion distance of Li ions. The initial discharge capacity of $628.7 \mathrm{~mA} \mathrm{~h} / \mathrm{g}$ was higher than that of graphite regardless the irreversible loss of first cycle. The defects and exposed edge planes of graphene sheets are efficient for the Li ion insertion augmented reversible capacity and capacitance retention.

Li et al. (2017b) prepared spherical porous carbon nanomaterials having uniform morphology from bituminous coal having a specific capacity of $1188.9 \mathrm{~mA} \mathrm{~h} / \mathrm{g}$. The large surface area decreases the lithium ion transportation distance and thereby improving capacity and cyclic stability. A reversible capacity of $844.9 \mathrm{~mA} \mathrm{~h} / \mathrm{g}$ was retained after 200 galvanostatic cycles. Porous graphene having high specific area $\left(640 \mathrm{~m}^{2} / \mathrm{g}\right)$ and micro-mesomacro pores was extracted from anthracite for high performance anode materials in LIBs (Xing et al. 2019). Graphene possess an outstanding cyclic performance with 98\% capacitance retention for 110 cycles and a reversible capacity of $770 \mathrm{~mA} \mathrm{~h} / \mathrm{g}$ at $0.1 \mathrm{C}$. The integrated pores structure and intrinsic electronic characteristics of coal based graphene ensures excellent diffusion and transportation of lithium ions.
Bituminous coal based carbon nanofibers (CNF) were also employed as a matrix for the uniform suspension of Molybdenum trioxide $\left(\mathrm{MoO}_{3}\right)$ nanoparticles having high theoretical capacity (Zhao et al. 2020). This nanocomposite could prevent volume expansion and sluggish electrode reaction kinetics caused by $\mathrm{MoO}_{3}$ particles that hinders transportation routes of ions. The $\mathrm{MoO}_{3} / \mathrm{CNF}$ demonstrated a high specific capacity of $801.1 \mathrm{~mA} \mathrm{~h} / \mathrm{g}$ at a current density of $0.5 \mathrm{~A} / \mathrm{g}$. Of the initial discharge capacity of $1107.5 \mathrm{~mA} \mathrm{~h} / \mathrm{g}$ at $0.1 \mathrm{~A} / \mathrm{g}, 99.5 \%$ of the discharge capacity could be recovered due to the stable cyclic performance of the nanocomposite. The fast electrode kinetics of the electrode was further confirmed through high value of diffusion coefficient (Fig. 8).

Carbon anodes for potassium ion batteries were prepared from bituminous coal by Xiao et al. (2019). The anode material retaining $260 \mathrm{~mA} \mathrm{~h} / \mathrm{g}$ under current density of $50 \mathrm{~mA} / \mathrm{g}$ indicates good electrochemical reversibility. A smaller diameter of semicircle was observed in the EIS technique indicating the lowest charge-transfer resistance resulting from the highest crystallinity of the coal. The microstructure of the coal based carbon constitutes mesopores and micropores which facilitates active storage sites for $\mathrm{K}^{+}$and diffusion of $\mathrm{K}^{+}$respectively. Even after 

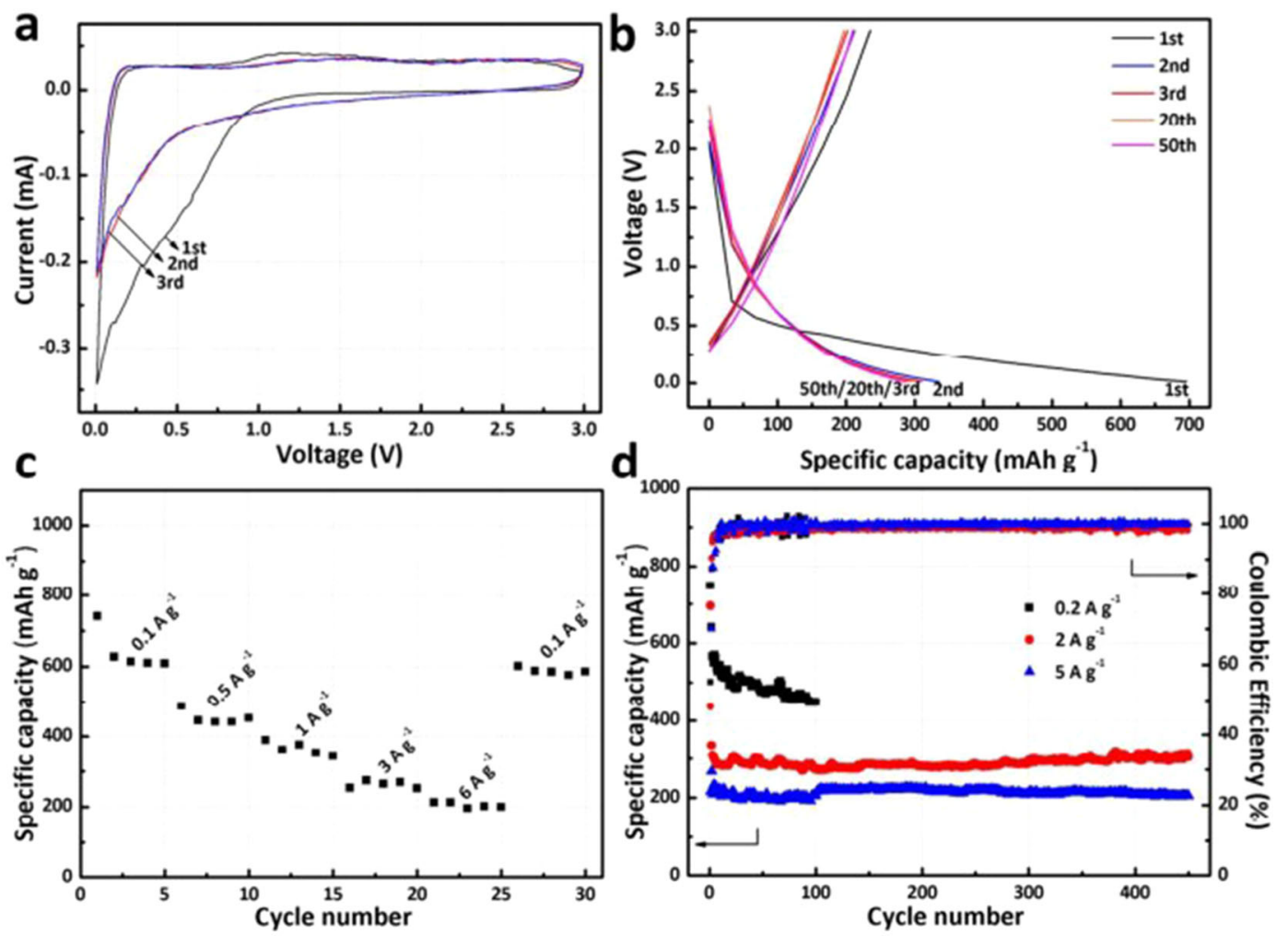

Fig. 7 a Cyclic voltammetry curves of porous carbon obtained from bituminous coal at $0.1 \mathrm{mV} / \mathrm{s}$ of various. b Charge-Discharge curves at $2 \mathrm{~A} /$ g. c Specific capacitance vs. cycle number. d Cyclic performance at $0.2 \mathrm{~A} / \mathrm{g}, 2 \mathrm{~A} / \mathrm{g}, 5 \mathrm{~A} / \mathrm{g}$ (Gao et al. 2018). (Reprinted with permission from the publisher)

1200 cycles, cyclic stability was maintained at $118 \mathrm{~mA} \mathrm{~h} / \mathrm{g}$ with retention of $68.6 \%$. Similarly, Carbon microcrystals/ CNT composite suitable for gravimetric and volumetric $\mathrm{Na}^{+}$storage was developed from needle coke as an alternative for $\mathrm{Li}$ ion batteries (Abou-Rjeily et al. 2019). Plentiful oxygen functional groups contribute to psuedocapacitance and also act as binder connecting active material. The volumetric capacity $626.6 \mathrm{~mA} \mathrm{~h} / \mathrm{g}$ delivered by the composite was 2-3 times higher than that of graphene and commercial graphite. Moreover, reversible specific capacity was calculated to be $309 \mathrm{~mA} \mathrm{~h} / \mathrm{g}$ and $130 \mathrm{~mA} \mathrm{~h} / \mathrm{g}$ for 100 cycles at $50 \mathrm{~mA} / \mathrm{g}$ and 2000 cycles at $2 \mathrm{~A} / \mathrm{g}$ respectively. This work demonstrates the prospects of utilizing the oxygen functional groups of coal based carbonaceous materials for the best of electrochemical capacity.

Huang et al. (2017) implemented heat-treated bituminous coal as anode material for both $\mathrm{Li}$ ion and sodium ion batteries. The thermal process carbonized the raw coal and delivers a pure anode with a reversible capacity of $223 \mathrm{~mA} \mathrm{~h} / \mathrm{g}$ and $409 \mathrm{~mA} \mathrm{~h} / \mathrm{g}$ for sodium ion and Lithium ion batteries respectively. The structural alteration induced in the coal through thermal annealing process provides a low-cost scenario for the fabrication of anode for largescale energy storage.

\subsection{Fuel cell}

An efficient and clean way of utilizing coal for the generation of energy is in fuel cells. In direct carbon fuel cell (DCFC), solid carbon is directly converted into electrical energy without combustion and hence reducing the emission of toxic gases. Any carbonaceous coal can be used as a fuel; but one with the higher carbon content and lower ash content will be appreciable for $100 \%$ efficiency. However, enhanced electrochemical reactivity is directly related to the disorderliness in the crystallinity of coal. Li et al. (2010) introduced various strategies for the modification of microstructure and surface properties of coal (bituminous) beneficial for the fuel performance in DCFC. Acid treatment of coal using $\mathrm{HNO}_{3}$ increases the electrochemical reactivity through the introduction of oxygen functional groups in the surface, but yields $\mathrm{CO}_{2}$. It can also assist with removal of ash for the protection of cell. Pyrolysis of carbonaceous coal can abolish the release of $\mathrm{CO}_{2}$, but lessen the electrochemical activity Ali et al. (2018) evaluated the performance of DCFC using sub-bituminous coal as fuel. It is found that the intrinsic surface properties of coal supplement to the cell performance. The enhanced reaction kinetics at the anode boundary due to the oxidation 

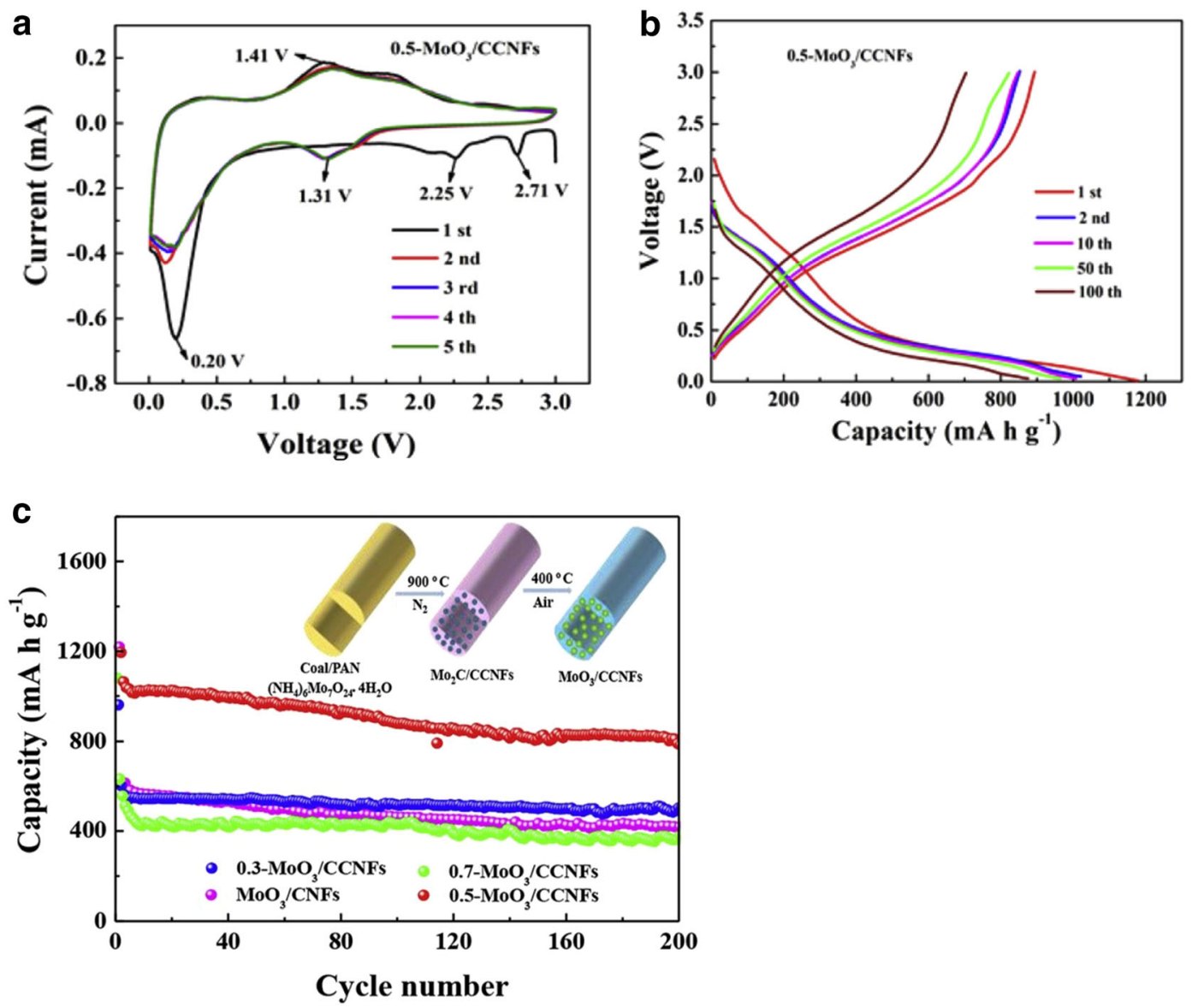

Fig. 8 a Cyclic voltammetry curves b Rate performance $\mathbf{c}$ long cyclic performance and coulombic efficiency of $\mathrm{MoO}_{3} / \mathrm{CNF}$ composite prepared from bituminous coal (Zhao et al. 2020). (Reprinted with permission from the publisher)

of carbon particles offers a maximum power density of $58 \mathrm{~mW} / \mathrm{cm}^{2}$ (Fig. 9).

Ash free coal (AFC) is prominent for DCFC due to its high accessible surface area, plentiful carboxyl functionalities on the surface and fewer content of ash (Okuyama et al. 2004). Vu and Lee (2016) reported the extraction of AFC from bituminous and sub-bituminous coal via solvent extraction method. Fuel cell could run successfully at $850{ }^{\circ} \mathrm{C}$ employing mixture of $\mathrm{AFC}$ as fuel and carbonate as electrolyte $\left(62 \mathrm{~mol} \% \mathrm{Li}_{2} \mathrm{CO}_{3}+38 \mathrm{~mol} \% \mathrm{~K}_{2} \mathrm{CO}_{3}\right)$. From the electrochemical study, an open-circuit voltage of $0.74 \mathrm{~V}$ and $0.61 \mathrm{~V}$ at a current density of $150 \mathrm{~mA} / \mathrm{cm}^{2}$ were observed for bituminous and sub-bituminous coal respectively. Stable performance of fuel cell was achieved by $\mathrm{Li}$ et al. (2016) using AFC as fuel. A gradual reduction in the operational temperature was also examined for the AFC using fuel cell in comparison to conventional carbon fuel. AFC also eliminates the need of carbonate catalyst for gasification. Effects of operating temperature on cell performance of an AFC based fuel cell was investigated by Kim et al. (2012). For a cell voltage of $1.1 \mathrm{~V}$ and temperature of $750{ }^{\circ} \mathrm{C}$, a maximum density of $2.5 \mathrm{~mW} / \mathrm{cm}^{2}$ was attained. At higher temperatures, coal exists in a liquid-like state favourable for improved activity of cell and decreased activation polarization.

\subsection{Electroanalytical chemistry}

Coal based carbonaceous materials can acts as an excellent modified matrix for the electroanalytical chemistry due to its good sensitivity, low detection limit stability and reproducibility. Annealed anthracite coal modified carbon electrode was used for the electrochemical detection of Rutin, an electroactive redox molecule (Huang et al. 2017). Rutin could be determined in the concentration range $0.001-10 \mu \mathrm{mol} / \mathrm{dm}^{3}$ with a detection limit of $0.2 \mathrm{nmmol} /$ $\mathrm{dm}^{3}$. In addition, annealed coal likewise possess electrocatalytic activity towards bio molecules such as uric acid and adenine in blood samples and urine samples. Through the process of annealing, numerous defectives sites were introduced into the coal which serve as the active sites for the transfer of electroactive species and henceforth increase in electrocatalytic current. Zhang et al. (2019) obtained multifunctional graphene-based carbon from anthracite 
through direct laser scribing. The developed graphene displayed excellent electrochemical sensitivity and high electrical conductivity. These properties enable the accurate electrochemical sensing of dopamine in the detection range of 5-40 $\mu \mathrm{M}$ (Fig. 10).

The authors reported preparation of few layer graphene from bituminous coal having high catalytic current beneficial for sensors (Kumar et al. 2017). Graphene coated carbon electrode showed excellent electrocatalytic activity desired for the oxidation of caffeine. It exhibited a wide detection range from 0.2 to $200 \mu \mathrm{M} / \mathrm{L}$ and lower detection limit of $90 \mathrm{nmmol} / \mathrm{L}$. Hence bituminous coal derived graphene could be a highly sensitive and selective electrochemical sensing platform for caffeine in commercially available soft drinks/food samples.

For instance, heteroatom modified carbon matrix for enhanced oxygen evolution reaction (OER) activity was developed from brown coal by Pan et al. (2019). When an optimum amount of transition metal element (Co) was added to the Nitrogen doped carbon, tendency of nanoparticles to agglomerate was negated and kinetic phenomenon was enhanced. The synergistic interaction of cobalt with nitrogen functional groups augments the catalysis towards OER under alkaline media. The support of the carbon substrate possibly supplemented the OER
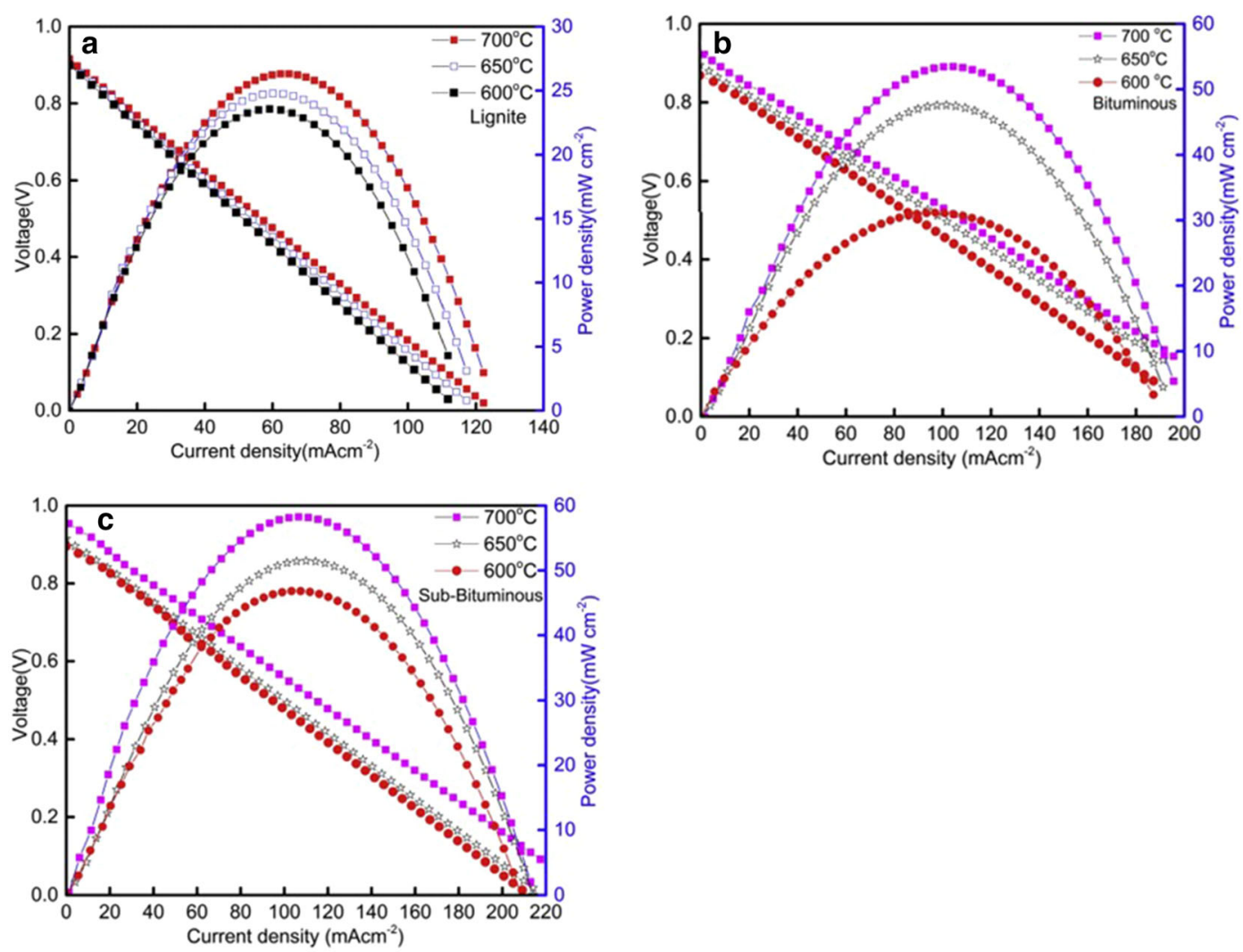

performance of the catalyst. Over potential of $0.370 \mathrm{~V}$ was noticed at $1 \mathrm{~mA} / \mathrm{cm}^{2}$ without much variation in the activity of the catalyst after $66 \mathrm{~h}$ of continuous galvanostatic polarization. Likewise, Nitrogen and Boron doped graphene quantum dots/graphene was synthesized by Huilong and group using anthracite as the carbon source (Fei et al. 2014). Nanoplatelets were assembled through hydrothermal treatment for enriching co-doping sites at GQDs and acquiring conductivity from graphene sheets. The kinetic current of the hybrid nanoplatelets was far higher than that of conventional electrocatalyst platinum loaded carbon. Under the continuous operation for $20,000 \mathrm{~s}$ using chronoamperometric technique, $73 \%$ of current was retained indicating the admirable durability. A positive onset potential of $15 \mathrm{mV}$ was observed for the oxygen reduction reaction activity.

\section{Conclusions}

The carbonaceous coal has been admitted as a basic, economic source of energy due to its high energy density, easy storage and low-cost. The traditional way of utilizing coal for energy consumption through combustion involves release of high concentration of toxic pollutants and has

Fig. 9 Performance of cells a Lignite b Bituminous c Sub-bituminous coal (Ali et al. 2018). (Reprinted with permission from the publisher) 

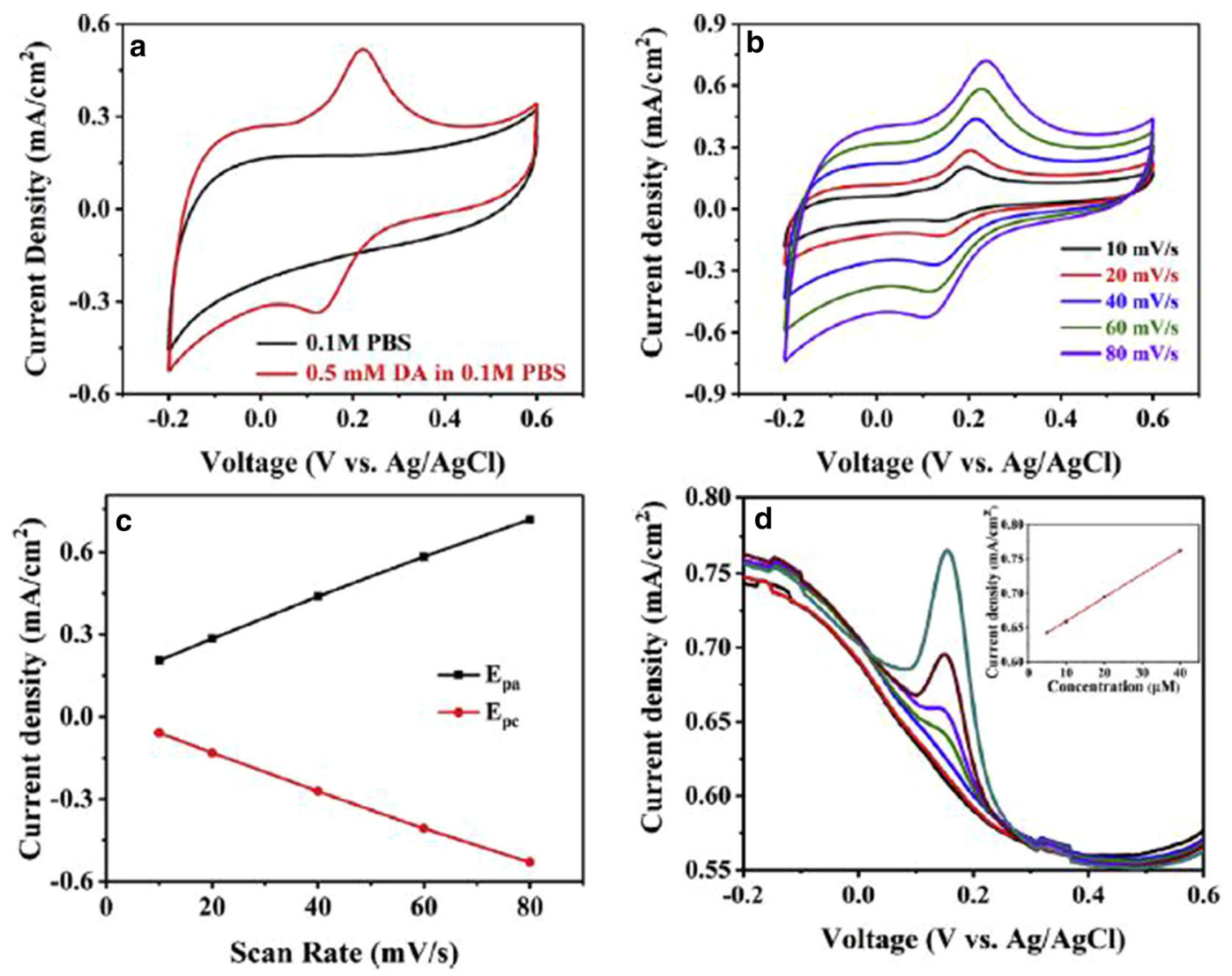

Fig. 10 a CV curves of electrode with and without addition of dopamine. b CV curves of electrode with $0.5 \mathrm{mM}$ dopamine with different scan rates. c Relationship between the redox peak current density and the scan rates. d DPV of electrode with different concentration of Dopamine (Zhang et al. 2019). (Reprinted with permission from the publisher)

lower yields and less efficiency. A competent mechanism is required for the effective utilization of coal as a green energy resource. The rank of coal, microstructures and surface chemistry are highly influential parameters for its electrochemical performance. The macromolecular skeleton of aromatic units and functional groups make coal an affordable precursor to replace graphite in mass production of carbon-based novel structures with potential applications. High carbon content, crystallinity, porous surface configuration, high specific surface area, defects and heteroatoms bestow carbonaceous coal as suitable matrix for supercapacitors, batteries, fuel cells and sensors. The electrochemical mechanism is greatly dependent on the accessible surface area and conductivity of electrodes. Coal derived nanocarbon can act as an efficient electrode material as it possesses numerous open pore distribution which enhance both surface area and capacitance. The inherent metallic impurities contribute an additional psuedocapacitance for increased wettability and reduced internal resistance of electrode with electrolyte. Hence carbon based material prepared from coal is a potential aspirant for competent electrode material in real life applications. The great demand for coal based nanocarbon construct a reliable approach for the conversion of ineffectual fossil fuel effluents into value added products.

Open Access This article is licensed under a Creative Commons Attribution 4.0 International License, which permits use, sharing, adaptation, distribution and reproduction in any medium or format, as long as you give appropriate credit to the original author(s) and the source, provide a link to the Creative Commons licence, and indicate if changes were made. The images or other third party material in this article are included in the article's Creative Commons licence, unless indicated otherwise in a credit line to the material. If material is not included in the article's Creative Commons licence and your intended use is not permitted by statutory regulation or exceeds the permitted use, you will need to obtain permission directly from the copyright holder. To view a copy of this licence, visit http://creativecommons. org/licenses/by/4.0/.

Funding The funding was provided by Department of Science and Technology, Ministry of Science and Technology (IF180596).

\section{References}

Abou-Rjeily J, Ait Laziz N, Autret-Lambert C et al (2019) Bituminous coal as low-cost anode materials for sodium ion and lithium ion batteries. Energy Technol 7(7):1900005 
Ali A, Bashir FS, Raza R et al (2018) Electrochemical study of composite materials for coal-based direct carbon fuel cell. Int $\mathbf{J}$ Hydrogen Energy 3(28):12900-12908

Awasthi K, Srivastava A, Srivastava ON (2005) Synthesis of carbon nanotubes. J Nanosci Nanotechnol 5(10):1616-1636

Awasthi S, Awasthi K, Ghosh AK et al (2015) Formation of single and multi-walled carbon nanotubes and graphene from Indian bituminous coal. Fuel 147:35-42

Benoy SM, Singh S, Pandey M et al (2020) Characterization of nanocarbon based electrode material derived from anthracite coal. Mater Res Exp 6(12):125624

Das T, Saikia BK, Baruah BP (2016a) Formation of carbon nano-balls and carbon nano-tubes from northeast Indian Tertiary coal: value added products from low grade coal. Gondwana Res 31:295-304

Das T, Boruah PK, Das MR et al (2016b) Formation of onion-like fullerene and chemically converted graphene-like nanosheets from low-quality coals: application in photocatalytic degradation of 2-nitrophenol. RSC Adv 6(42):35177-35190

Das T, Chauhan H, Deka S (2017) Promising carbon nanosheet-based supercapacitor electrode materials from low-grade coals. Microporous Mesoporous Mater 253:80-90

Elcey CD, Manoj B (2016) Graphitization of coal by bio-solubilization: structure probe by Raman spectroscopy. Asian J Chem 28(7): 1557-1560

Fei H, Ye R, Ye G (2014) Boron- and nitrogen-doped graphene quantum dots/graphene hybrid nanoplatelets as efficient electrocatalysts for oxygen reduction. ACS Nano 8(10):10837-10843

Fernández-García L, Álvarez P, Pérez-Mas AM et al (2017) Peculiarities of the production of graphene oxides with controlled properties from industrial coal liquids. Fuel 203:253-260

Foygel M, Morris RD, Anez D et al (2005) Theoretical and computational studies of carbon nanotube composites and suspensions: electrical and thermal conductivity. Phys Rev B 71(10): 104201

Gao F, Qu J, Zhao Z et al (2014) A green strategy for the synthesis of graphene supported $\mathrm{Mn}_{3} \mathrm{O}_{4}$ nanocomposites from graphitized coal and their supercapacitor application. Carbon 80:640-650

Gao S, Tang Y, Wang L et al (2018) Coal-based hierarchical porous carbon synthesized with a soluble salt self-assembly-assisted method for high performance supercapacitors and Li-ion batteries. ACS Sustain Chem Eng 6(3):3255-3263

Haenel MW (1992) Recent progress in coal structure research. Fuel 71(11):1211-1223

He X, Zhang H, Zhang H et al (2014) Direct synthesis of 3D hollow porous graphene balls from coal tar pitch for high performance supercapacitors. J Mater Chem A 2(46):19633-19640

$\mathrm{He}$ X, Li X, Ma H et al (2017) ZnO template strategy for the synthesis of 3D interconnected graphene nanocapsules from coal tar pitch as supercapacitor electrode materials. J Power Sources 340:183-191

Huang J, Zeng Q, Bai S et al (2017) Application of coal in electrochemical sensing. Anal Chem 89(16):8358-8365

Jurewicz K, Pietrzak R, Nowicki P et al (2008) Capacitance behaviour of brown coal based active carbon modified through chemical reaction with urea. Electrochim Acta 53(16):5469-5475

Kim JP, Choi HK, Chang YJ et al (2012) Feasibility of using ash-free coal in a solid-oxide-electrolyte direct carbon fuel cell. Int $\mathrm{J}$ Hydrogen Energy 37:11401-11408

Kumar R, Singh RK, Ghosh AK et al (2013) Synthesis of coal-derived single-walled carbon nanotube from coal by varying the ratio of $\mathrm{Zr} / \mathrm{Ni}$ as bimetallic catalyst. J Nanopart Res 15(1):1406

Kumar ES, Sivasankar V, Sureshbabu R et al (2017) Facile synthesis of few layer graphene from bituminous coal and its application towards electrochemical sensing of caffeine. Adv Mater Lett $8(3): 239-245$
Kundu N, Bhunia P, Sarkar S, Biswas P (2020) Highly fluorescent carbon dots from quinoline insoluble residues in coal tar. Opt Mater 100:109638

Lee CG, Kim WK (2015) Oxidation of ash-free coal in a direct carbon fuel cell. Int J Hydrogen Energy 40(15):5475-5481

Li X, Zhu Z, De Marco R et al (2010) Modification of coal as a fuel for the direct carbon fuel cell. JPhys Chem A 114(11):3855-3862

Li YF, Qiu JS, Zhao ZB et al (2012) Bamboo-shaped carbon tubes from coal. Chem Phys Lett 366(5-6):544-550

Li Z, Qin P, Wang L (2016) Amine-enriched graphene quantum dots for high-pseudocapacitance supercapacitors. Electrochim Acta 208:260-266

Li J, Cao Y, Wang L et al (2017a) Cost-effective synthesis of bamboo-structure carbon nanotubes from coal for reversible lithium storage. RSC Adv 7(55):34770-34775

Li J, Cao YL, Wang LX (2017b) Performance of coal-derived spherical porous carbon as anode materials for lithium ion batteries. J Inorg Mater 32(9):909-915

Liu XM, dong Huang Z, woon Oh S et al (2012) Carbon nanotube (CNT)-based composites as electrode material for rechargeable Li-ion batteries: a review. Compos Sci Technol 72(2):121-144

Lu Y, Zhang S, Yin J et al (2017) Mesoporous activated carbon materials with ultrahigh mesopore volume and effective specific surface area for high performance supercapacitors. Carbon 124:64-71

Manoj B (2016) A comprehensive analysis of various structural parameters of Indian coals with the aid of advanced analytical tools. Int J Coal Sci Technol 3(2):123-132

Manoj B, Kunjomana AG (2012) Study of stacking structure of amorphous carbon by X-ray diffraction technique. Int $\mathrm{J}$ Electrochem Sci 7(4):3127-3134

Manoj B, Kunjomana AG (2014) Systematic investigations of graphene layers in sub-bituminous coal. RussJ Appl Chem 87(11):1726-1733

Manoj B, Ashlin MR, George Thomas C (2017) Tuneable direct bandgap photoluminescent organic semiconducting nanoparticles from lignite. Sci Rep 7(1):1-9

Manoj B, Ashlin MR, George Thomas C (2018) Tailoring of low grade coal to fluorescent nanocarbon structure and their potential as a glucose sensor. Sci Rep 8(1):13891

Mathews JP, Chaffee AL (2012) The molecular representations of coal-a review. Fuel 96:1-4

Meng J, Li S, Niu J (2019) Crystallite structure characteristics and its influence on methane adsorption for different rank coals. ACS Omega 4(24):20762-20772

Miao S, Zhao H, Kang $M$ et al (2019) High gravimetric and volumetric sodium storage in a functionalized coal-based microcrystal/CNT binder-free electrode. Chem Commun 55(55):7954-7957

O'Keefe JM, Bechtel A, Christanis K, Dai S, DiMichele WA, Eble CF, Esterle JS, Mastalerz M, Raymond AL, Valentim BV, Wagner NJ (2013) On the fundamental difference between coal rank and coal type. Int J Coal Geol 118:58-87

Okuyama N, Komatsu N, Shigehisa T et al (2004) Hyper-coal process to produce the ash-free coal. Fuel Process Technol 85(8-10):947-967

Pakhira B, Ghosh S, Maity S et al (2015) Extraction of preformed graphene oxide from coal: its clenched fist form entrapping large molecules. RSC Adv 5(108):89076-89082

Pan H, Wu D, Huang X (2019) Microwave-assisted synthesis of Co/ CoOx supported on earth-abundant coal-derived carbon for electrocatalysis of oxygen evolution. $\mathrm{J}$ Electrochem Soc 166(8):479-486

Peng J, Gao W, Gupta BK et al (2012) Graphene quantum dots derived from carbon fibers. Nano Lett 12(2):844-849 
Qing Y, Jiang Y, Lin H et al (2019) Boosting the supercapacitor performance of activated carbon by constructing overall conductive networks using graphene quantum dots. J Mater Chem A 7(11):6021-6027

Riya T, Balachandran M (2020) Luminescence and energy storage characteristics of coke-based graphite oxide. Mater Chem Phys 257:123854

Riya T, Manoj B (2020) Fabrication approaches for graphene in supercapacitors. In: Graphene as energy storage material for supercapacitors, vol 64. Materials Research Foundations, Millersville, PA, pp 1-24

Saikia BK, Boruah RK et al (2009) A X-ray diffraction analysis on graphene layers of Assam coal. J Chem Sci 121(1):103-106

Savitskii DP (2017) Preparation and characterization of colloidal dispersions of graphene-like structures from different ranks of coals. J Fuel Chem Technol 45(8):897-907

Shen J, Zhu Y, Yang X et al (2012) Graphene quantum dots: emergent nanolights for bioimaging, sensors, catalysis and photovoltaic devices. Chem Commun 48(31):3686-3699

Sierra U, Álvarez P, Blanco C (2016) Cokes of different origin as precursors of graphene oxide. Fuel 166:400-403

Singh A, Ojha AK (2020) Coal derived graphene as an efficient supercapacitor electrode material. Chem Phys 530:110607

Stankovich S, Dikin DA, Dommett GH et al (2006) Graphene-based composite materials. Nature 442(7100):282-286

Tong F, Jia W, Pan Y et al (2019) A green approach to prepare hierarchical porous carbon nanofibers from coal for highperformance supercapacitors. RSC Adv 9(11):6184-6192

Vijapur SH, Wang D, Ingram DC et al (2017) An investigation of growth mechanism of coal derived graphene films. Mater Today Commun 11:147-155

Vu DL, Lee CG (2016) Oxidation of ash-free coal from subbituminous and bituminous coals in a direct carbon fuel cell. Korean J Chem Eng 33(2):507-513

Wang H, Zhu H, Li Y et al (2019) Hierarchical porous carbon derived from carboxylated coal-tar pitch for electrical double-layer capacitors. RSC Adv 9(50):29131-29140

Worsley MA, Kucheyev SO, Mason HE et al (2012) Mechanically robust 3D graphene macroassembly with high surface area. Chem Commun 48(67):8428-8430
Wu ZS, Sun Y, Tan YZ et al (2012) Three-dimensional graphenebased macro- and mesoporous frameworks for high-performance electrochemical capacitive energy storage. J Am Chem Soc 134(48):19532-19535

Wu Y, Ma Y, Wang Y et al (2013) Efficient and large scale synthesis of graphene from coal and its film electrical properties studies. J Nanosci Nanotechnol 13(2):929-932

Xiao N, Zhang X, Liu C et al (2019) Coal-based carbon anodes for high-performance potassium-ion batteries. Carbon 147:574-581

Xing B, Zeng H, Huang G et al (2019) Porous graphene prepared from anthracite as high performance anode materials for lithiumion battery applications. J Alloys Compd 779:202-211

Xu H, Lin Q, Zhou T et al (2014) Facile preparation of graphene nanosheets by pyrolysis of coal-tar pitch with the presence of aluminum. J Anal Appl Pyrol 110:481-485

Ye R, Xiang C, Lin J, Peng Z, Huang K, Yan Z, Cook NP, Samuel EL, Hwang CC, Ruan G, Ceriotti G (2013) Coal as an abundant source of graphene quantum dots. Nat Commun 4:2943

Zhang Z, Zhang J, Chen N et al (2012) Graphene quantum dots: an emerging material for energy-related applications and beyond. Energy Environ Sci 5(10):8869-8890

Zhang S, Zhu J, Qing Y et al (2017) Construction of hierarchical porous carbon nanosheets from template-assisted assembly of coal-based graphene quantum dots for high performance supercapacitor electrodes. Mater Today Energy 6:36-45

Zhang C, Xie Y, Zhang C et al (2019) Upgrading coal to multifunctional graphene based materials by direct laser scribing. Carbon 153:585-591

Zhao X, Jia W, Wu X et al (2020) Ultrafine $\mathrm{MoO}_{3}$ anchored in coalbased carbon nanofiber as anode for advanced lithium-ion batteries. Carbon 156:445-452

Zhou Q, Zhao Z, Zhang Y et al (2012) Graphene sheets from graphitized anthracite coal: preparation, decoration, and application. Energy Fuels 26(8):5186-5192

Zhu J, Zhang X, Zhang S et al (2017) Preparation of cobalt/coalbased activated carbon composites with synergistic electrochemical performance. Int J Electrochem Sci 12:3991-4000 